\title{
MEME E AFORIZAÇÃO: UMA ABORDAGEM DISCURSIVA DA ICONOTEXTUALIDADE DIGITAL
}

\author{
GUILHERME DE CAMARGO SCALZILLI*
}

\begin{abstract}
RESUMO: Este artigo busca reunir subsídios para uma análise dos mecanismos de aforização presentes nos memes digitais. Questionando a terminologia utilizada para definir um repertório tão vasto e complexo, proponho considerar o meme a partir de recorte baseado no conceito de iconotexto, herdado dos campos publicitário e jornalístico. Os critérios de abordagem seguem a linha francesa de Análise do Discurso, com ênfase no trabalho de Dominique Maingueneau. Os exemplos possuem natureza política e foram selecionados segundo a contribuição que podem oferecer ao estudo das modalidades primária e secundária de aforização.

Palavras-chave: Meme; Aforização; Análise do discurso.
\end{abstract}

\begin{abstract}
This paper intends to establish theoretical basis for a analysis of the aphorization mechanisms present in internet memes. Questioning the terminology used to define such a vast and complex repertoire, I propose to consider the internet meme inside a framework based on the concept of iconotext, inherited from the advertising and journalistic fields. The criteria of approach follow the French lineage of Discourse Analysis, with emphasis on the work of Dominique Maingueneau. The examples belong to a political kind of iconotext, and have been selected according to their contribution to the study of the primary and secondary modalities of aphorization.
\end{abstract}

Keywords: Internet Meme; Aphorization; Discourse analysis

\section{INTRODUÇÃO}

As pesquisas sobre questões da discursividade no universo digital enfrentam o desafio de estabelecer recortes analíticos em meio à profusão de linguagens e formatos que circulam nas diversas vias de compartilhamento da internet. Essa dificuldade se agrava ao lidarmos com nomenclaturas que procuram unificar repertórios demasiado heterogêneos, inserindo-os numa espécie de fluidez conceitual pouco frutífera para o estabelecimento de parâmetros teóricos de abordagem. É o que notamos com a denominação "meme", de uso maciço nos intercâmbios virtuais cotidianos, mas insuficiente para esclarecer as peculiaridades dos diversos objetos a que se destina.

Parece desnecessário reiterar a importância das transformações advindas com os processos cotidianos de intercâmbio virtual. Inúmeras vias de reflexão

" Universidade de São Paulo (USP), São Paulo, SP, Brasil. scalzilli.guilherme@gmail.com 
foram abertas pelo desenvolvimento de mecanismos comunicacionais amplamente acessíveis, não apenas para a fruição, mas principalmente para a interação criativa dos participantes. As redes polifônicas tecidas na reconfiguração e na reciclagem de enunciados, para não mencionar as itinerâncias da hipertextualidade, abrem perspectivas interdisciplinares de horizontes ainda pouco definidos ou sequer esboçados.

Ao contrário do que sugerem algumas narrativas apologéticas em torno do ineditismo técnico dos conteúdos digitais, no entanto, eles nem sempre se articulam em torno de processos significantes novos ou "revolucionários". Em outras palavras, a natureza digital dos objetos não justifica uma concepção metodológica aprioristicamente diversa daquela dedicada a materiais similares dos suportes físicos, pois o repertório audiovisual que circula na internet continua em boa medida tributário de modalidades enunciativas e estratégias de persuasão anteriores ao advento da tecnologia computacional. São os casos, por exemplo, das heranças do jornalismo e da publicidade, apesar de certa nomenclatura generalizante que ajuda a naturalizá-las como características intrínsecas à própria linguagem da internet.

O tema é tratado com profundidade, em viés cognitivista, por Lev Manovich (2001). Embora se dedique a salientar as muitas perspectivas abertas pelas novas mídias, o autor aponta nelas uma conversão de padrões analógicos do passado, um tipo de atualização digital de regimes de visualidade preestabelecidos (p. 50), especialmente o cinema e o suporte gráfico:

No caso do "mundo impresso", também me refiro a um leque de convenções que se desenvolveram durante vários séculos (algumas antes mesmo da invenção da imprensa), e que hoje são compartilhadas por numerosas formas de material impresso, das revistas ao manuais de instrução - uma página retangular contendo uma ou mais colunas de texto, figuras ou outros gráficos emoldurados pelo texto, páginas que seguem umas às outras em sequência, uma tabela de conteúdos e índices" (MANOVICH, 2001, p. 71).

Se já serviam como "interfaces metalinguísticas e culturais" da informática (p. 74), os modelos tradicionais de textualidade também foram incorporados pelo universo virtual através de um imenso repertório significativo no qual o sentido de "texto", a princípio, permaneceu inalterado. O que mudou foi a organização dos "textos" no acervo disponível, pois os limites físicos, as hierarquias e as linearidades típicas da configuração anterior deram lugar à "superfície plana e infinita" da internet (p. 76-77). Isto significa que a eventual superação das estruturas retóricas consagradas depende fundamentalmente do nível de influência que as opções interativas exercem sobre o conteúdo acessado (p. 78).

Mas não convém supervalorizar o alcance de tais novidades. Mesmo que as ferramentas presentes em quase todos os dispositivos eletrônicos permitam uma criação disseminada de mensagens visuais, elas amiúde assimilam e reciclam procedimentos de interpelação da audiência característicos dos universos publicitário, jornalístico e humorístico, incorporando também muitos de seus códigos verbais e imagéticos. É a partir de uma ancoragem nos padrões enunciativos pré-digitais, portanto, que os memes se fazem legíveis para o público, 
pelo menos ao nível imediato de reconhecimento e interpretação das mensagens. $\mathrm{O}$ vínculo fica bastante claro, sob o prisma da iconotextualidade, nos objetos elaborados com a superposição de imagens estáticas e complementos textuais, em geral desprovidos de ligações externas ${ }^{1}$.

Sugiro aqui algumas vias possíveis dessa abordagem, sem a pretensão de esgotá-las ou de reduzir o cabedal analítico do tema, particularmente no que concerne aos múltiplos desdobramentos abertos pela semiótica. Inicio problematizando a fragilidade da noção consagrada de meme e proponho considerar seu amplo universo a partir de um recorte baseado na tradição do iconotexto. Em seguida, tomando como via conceitual a Análise do Discurso de linha francesa, com destaque para a obra de Dominique Maingueneau, esboço uma aproximação do meme iconotextual sob os prismas da destacabilidade e da aforização, tópicos que protagonizam vários trabalhos desse autor.

\section{ARMADILHAS DA NOMENCLATURA}

A palavra "meme" foi cunhada inicialmente por Richard Dawkins, etólogo de linha darwiniana, em seu conhecido livro "O gene egoísta" (1979). Advertindo que o gene não é a única base da evolução humana, Dawkins adiciona a ele um outro tipo de replicador, o meme, responsável pela transmissão de heranças culturais. O substantivo está associado tanto à replicação da memória quanto à imitação de modelos que a constituem: “exemplos de memes são melodias, ideias, 'slogans', modas do vestuário, maneiras de fazer potes ou de construir arcos" (p. 214).

$\mathrm{O}$ termo gerou uma área de estudos conhecida como memética. Preservando o amplo escopo inaugurado por Dawkins, o interesse da memética envolve "as ideias, as estruturas cerebrais que estabelecem essas ideias, os comportamentos que essas estruturas cerebrais produzem e suas versões em livros, receitas, mapas e partituras" (BLACKMORE, 1999, p. 66). Mas é importante salientar que a "informação sendo copiada de uma pessoa para outra" ganha características de meme apenas quando longeva (resistente à obsolescência no fluxo do imediatismo), fecunda (geradora de muitas reciclagens) e fiel à matriz que o originou (p. 204).

Esses desenvolvimentos conceituais trazem dois obstáculos para a adoção do meme como tópico de análise.

O primeiro está ligado à abrangência universalizante da formulação. Envolvendo melodias, preceitos religiosos e científicos, hábitos ancestrais, obras literárias e outras tantas produções culturais (DAWKINS, 1979, p. 219), a noção de meme alcança um horizonte quase inapreensível, que decerto inclui os objetos transmitidos digitalmente, mas não serve para defini-los sob qualquer parâmetro de singularidade. Associada às próprias estruturas que geram e reciclam todas

1 "Ligações externas" no sentido hipertextual usado por Manovich para qualificar a inovação itinerante da experiência de leitura na internet. É discutível até que ponto a ocorrência do hipertexto ou mesmo as ferramentas de interação das redes digitais ("curtir", comentar, compartilhar, etc.) influiriam nas análises aqui propostas. $\mathrm{O}$ recorte adotado ajuda não apenas a focalizar a abordagem, mas a relativizar a ideia da onipresença da hipertextualidade nos processos de significação da internet. 
as ideias e práticas sociais, a definição de meme redunda numa generalização tautológica de pouca serventia para delimitar fenômenos específicos de interesse.

Por outro lado, as faculdades de permanência e reprodutibilidade exigidas para definir os memes necessitam de instrumentais de aferição e critérios comparativos dificilmente aplicáveis em qualquer escala, menos ainda na amplidão da internet. Seria impossível afirmar com segurança que a circulação digital de determinada imagem tem alcance merecedor da alcunha "meme", tampouco estabelecer o seu grau de originalidade ou de fidelidade a fontes primárias. Um objeto pode chegar ao nosso conhecimento passando por uma rede mínima de intercâmbio, quiçá irrelevante do ponto de vista das trocas virtuais, e mesmo assim apresentar profícuas redes interpretativas. Encaixá-lo em outro neologismo não resolveria o problema.

As dificuldades ficam mais claras se tentarmos conciliar essas definições com o repertório linguístico, identificando na ideia de meme uma reconfiguração de qualidades há muito verificadas nas trocas linguageiras. Mikhail Bakhtin (2003), para citar um exemplo canônico, mostra que "a experiência discursiva individual de qualquer pessoa se forma e se desenvolve em uma interação constante e contínua com os enunciados individuais dos outros" (p. 294), e que "todo enunciado completo é um elo na cadeia discursiva de determinado campo" (p. 296). Ainda que aceitássemos que a noção de Dawkins constitui um simulacro do dialogismo característico da interdiscursividade, precisaríamos negar que ele se reduz a determinados fenômenos de linguagem, como se houvesse outros que não desfrutam da prerrogativa.

É possível que esses dilemas fiquem obsoletos antes de encontrarem alguma solução. No vocabulário cotidiano dos usuários, com reflexos na esfera acadêmica, parece haver uma tendência à consolidação do rótulo "meme" para quaisquer objetos audiovisuais transmitidos digitalmente. Embora o hábito estabeleça critérios técnicos e pragmáticos para o uso da denominação, convém assimilá-la de maneira cuidadosa, mantendo em perspectiva o papel que a terminologia homogeneizante e simplificadora desempenha no discurso apologético das inovações digitais. $\mathrm{O}$ fascínio acrítico diante de um campo tão heterogêneo corre o risco de ignorar que objetos de naturezas díspares e complexas exigem metodologias específicas de abordagem, ainda que elas possam relativizar o ineditismo das práticas discursivas sob as novas tecnologias.

\section{O MEME ENQUANTO ICONOTEXTO}

As análises aqui propostas coadunam com a acepção hegemônica, mas recortam o amplo universo associado ao meme para tratar de uma categoria específica de material iconográfico propagado através da internet. Estabelecida por necessidade operacional e adequação às especificidades do objeto, essa delimitação permitirá abordá-lo segundo o conceito de iconotexto, de ampla utilização nos estudos midiáticos, em especial nos trabalhos sobre os discursos publicitário e jornalístico. 
Conhecido pelo menos desde as figuras de livros infantis do século XIX, o iconotexto desenvolveu-se para as mais variadas práticas criativas, acompanhando o aprimoramento das técnicas de diagramação e reprodução da cultura impressa. Nas artes plásticas, nas histórias em quadrinhos, nos anúncios, nas páginas noticiosas e, finalmente, na multiplicidade significativa da internet, a dimensão iconotextual adquiriu onipresença que a torna praticamente indissociável dos próprios regimes contemporâneos de visualidade.

"Objeto discursivo plurissemiótico", o iconotexto apresenta uma unidade formada por duas dimensões complementares, imagem e enunciado verbal, emolduradas e isoladas através de variáveis recursos gráficos. Como resultado desse encontro, "o linguístico e o icônico se unem numa totalidade inseparável, mas na qual cada um conserva sua própria especificidade", formando artefatos cuja coerência se articula numa tensão dialógica entre o plástico e o verbal (LUGRIN, 2006, p. 65-66).

Abordando imagens publicitárias de natureza iconotextual, Roland Barthes (1999) vê nelas um amálgama significativo gerado pela mensagem linguística, pela imagem denotada e pela imagem conotada (p. 31). Na dimensão linguística, interessa-nos a coexistência dialética de dois tipos de relação texto-imagem. De um lado, o texto exercendo uma função de comentário ou de "fixação" paratextual, comum nos intertítulos e legendas, com "valor repressivo em relação à liberdade dos significados da imagem" (p. 33, grifo do autor). De outro lado, um elo de complementaridade, que Barthes chama de "relais", onde a "unidade da mensagem é feita em um nível superior: o da história, o da anedota, o da diegese" (p. 34).

A denotação está ligada ao reconhecimento imediato dos sujeitos, objetos e cenários retratados. Advém da presunção de transparência do registro fotográfico, ou do nexo que ele estabelece entre significantes e significados, fornecendo uma "mensagem sem código" que "naturaliza a mensagem simbólica, inocenta o artifício semântico" da conotação (p. 36-37). Esta se desenvolve numa esfera propriamente cultural, a partir de códigos variáveis segundo regiões, circunstâncias, etc. A confluência de tais códigos estabelece a "retórica da imagem", conjunto de conotadores que resulta na "face significante da ideologia" (p. 40).

A transposição do universo conceitual barthesiano ao campo da discursividade mereceria trabalho à parte, mas o esboço apresentado já fornece pressupostos úteis para as reflexões a seguir. Basta manter em perspectiva o funcionamento simultâneo dos três níveis de significação, o linguístico, o denotativo e o conotativo, com a ressalva de que o dito "sistema cultural de conotação" não exige necessariamente a visada "ideológica" de Barthes, podendo ser apreendido como domínio de uma interdiscursividade com horizontes amplos e multifacetados.

A abordagem iconotextual do meme também ajuda a compreender como o procedimento aforizante dos objetos selecionados se distingue de um tipo de aforização muito comum nos retratismos jornalístico e publicitário, onde "o aforizador associado a um rosto se dirige diretamente ao leitor", apresentandose "como locutor no mundo sublunar e como aforizador em majestade" (MAINGUENEAU, 2014, p. 41, grifos do autor). Cada objeto abarca então dois 
destacamentos, o iconográfico e o textual, de cujo reforço mútuo advém uma clara identificação do enunciador (idem, p. 46).

Nossas figuras realizam uma aforização pertencente a outra esfera ética, no sentido de constituir seu éthos enunciativo sem o auxílio da representação fotográfica do "locutor" iconotextual. Estamos próximos daquilo que Maingueneau chama de aforização-eco, "na qual a frase não verbal se apresenta como o traço de uma aforização prévia completa, que, na realidade, é construída por essa própria remissão" (ibidem, p. 54). Mas, para todos os efeitos, a aforizaçãoeco e a enunciação aforizante original possuem o mesmo fiador. Nos exemplos selecionados, o éthos do aforizador se apresenta como responsável pelo conjunto da unidade iconotextual, não apenas pelo texto pertencente a ela, inclusive porque às vezes essa transposição caracteriza um afastamento significativo da enunciação primeira. Trata-se então de buscar a dimensão ética do iconotexto num âmbito conotativo que ultrapassa os componentes linguísticos e imagéticos dos objetos, embora seja indissociável deles.

\section{ALGUNS CASOS DE AFORIZAÇÃO ICONOTEXTUAL}

Dominique Maingueneau (2010) divide os tipos de destacamento enunciativo segundo sua inserção em regimes "textualizantes" ou "aforizantes", distinguíveis através das respectivas relações com as lógicas textuais e genéricas do discurso. $\mathrm{O}$ primeiro tipo envolve enunciados "destacáveis" através de modalizações efetuadas pelo próprio locutor-fonte. Trata-se da chamada "sobreasseveração", que, embora de uso disseminado nos suportes midiáticos, inclusive na esfera iconotextual, não é pertinente para a análise dos objetos selecionados.

O interesse pelo aspecto aforizante dos memes reside na "pretensão ilocutória" da aforização, como assevera Maingueneau, "de ser uma fala absoluta, sem contexto, mas convocada em um texto que, por natureza, não é absoluto" (idem, p. 17-18). Assimilando enunciados destacados aprioristicamente, que desfrutam de certa autonomia significativa, os iconotextos aqui reunidos apresentam-se como oriundos de outras cenas de enunciação, escapando às tessituras coercitivas dos gêneros discursivos originais (MAINGUENEAU, 2014, p. 35-40).

Reúno exemplos dos dois tipos de aforização teorizados por Maingueneau. Inicialmente descrevo as aforizações primárias, oriundas de destacamentos "constitutivos", que "não possuem contexto situacional nem cotexto original" (MAINGUENEAU, 2012, p. 1-2). São os casos do provérbio (figura 1) e do slogan (figura 2). Em seguida abordo as aforizações secundárias, ligadas a destacamentos extraídos de textos específicos e próximos de "uma lógica de citação" (MAINGUENEAU, 2008, p. 10). A manchete de um veículo informativo (figura 3) e o trecho de uma conversa telefônica divulgada pela imprensa (figura 4), ainda que reconfigurados, pertencem a esse tipo.

Todos os exemplos se inserem numa interdiscursividade de natureza política e se enquadram no fenômeno que Maingueneau qualifica de particitação. O termo, que agrega os sentidos de participação e citação, abarca enunciados memorizáveis, 
autônomos, desprovidos de indicações de fonte e ligados a um tesauro de referência. Esse repertório de conhecimentos mobiliza a adesão de um auditório universal, que se orienta pela presunção de veracidade e autoridade do "hiperenunciador" característico da aforização (idem, p. 69-70). O sucesso replicador de um meme, como aliás de todo iconotexto com natureza retórico-persuasiva, está ligado à eficácia sedutora do éthos constituído através do hiperenunciador.

A aforização primária, destacada "por natureza", possui um viés generalizante que permite a sua aplicação a circunstâncias muito diversificadas. São as peculiaridades da situação de enunciação que instruem o sentido da aforização e reciprocamente recebem desta um complemento significativo (MAINGUENEAU, 2011, p. 19). Isso explica por que o reconhecimento imediato de um provérbio como "Diga-me com quem andas que te direi quem és" (figura 1), de ampla disseminação nos intercâmbios linguageiros, propõe uma associação entre os sujeitos retratados que ultrapassa a denotação indicativa do conjunto fotográfico, isto é, de um encontro de ex-presidentes da República.

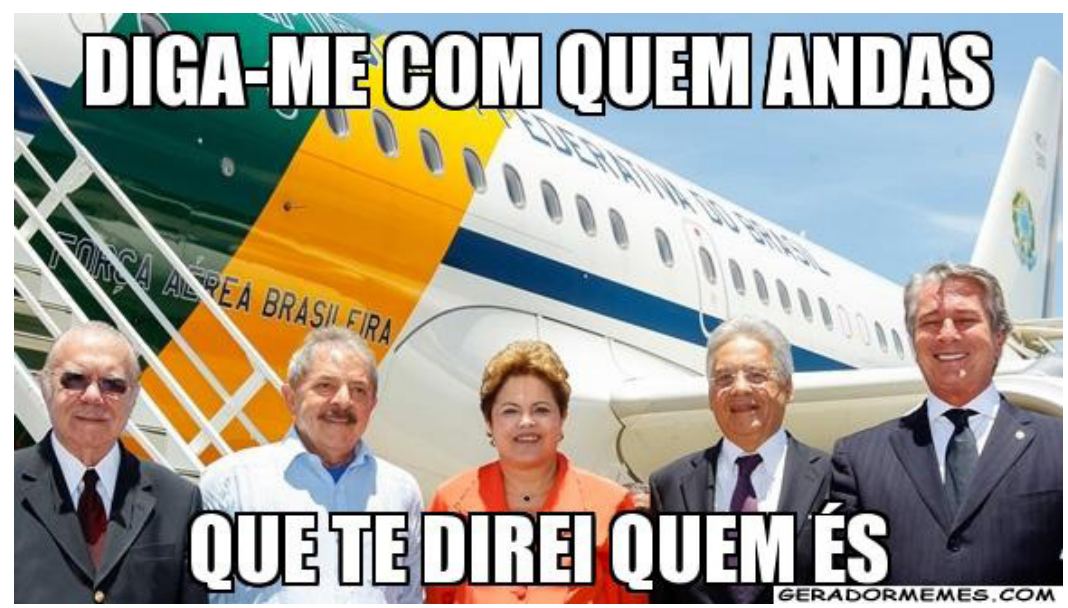

Figura 1

As expressões sorridentes e o símbolo ostentatório da aeronave ganham significado especial quando articulados entre si e com a admoestação crítica do hiperenunciador. O próprio ato de enunciá-la desloca o conhecimento enciclopédico do auditório acerca das diferenças ideológicas dos personagens para o âmbito de certa formação discursiva articulada em torno da inexorável similitude negativa dos líderes políticos ${ }^{2}$. A mensagem denotativa "são todos iguais" dialoga com o contexto do impeachment de Dilma Rousseff, sugerindo uma tomada de posição nos debates que agitaram o país.

${ }^{2}$ Por sua natureza "não-tópica", segundo as acepções de Maingueneau, insiro o discurso antipolítico no escopo da formação discursiva (MAINGUENEAU, 2007, p. 32). Esse é caso único no corpus iconotextual abordado. Os outros exemplos parecem mais próximos de unidades "tópicas", especificamente de "posicionamentos" inseparáveis dos respectivos contextos de enunciação. 
Outra forma de aforização primária é o slogan, que Maingueneau (2008, p. 103) situa entre as "particitações de grupo". Na figura 2, a particitação militante se realiza através de um enunciador coletivo, identificado com o PSDB, ou, mais precisamente, com a campanha presidencial de Aécio Neves em 2014. Não se trata de uma peça publicitária oficial, mas de uma apropriação de imagem particularmente emblemática da campanha de Barak Obama à presidência dos EUA. A identificação é induzida através do cromatismo em azul e vermelho, da diagramação (o retrato estilizado e os tipos em caixa alta e sem serifas) e, finalmente, do jargão "Uai we can", que alude ao "Yes we can" ("sim, nós podemos") do modelo estadunidense.

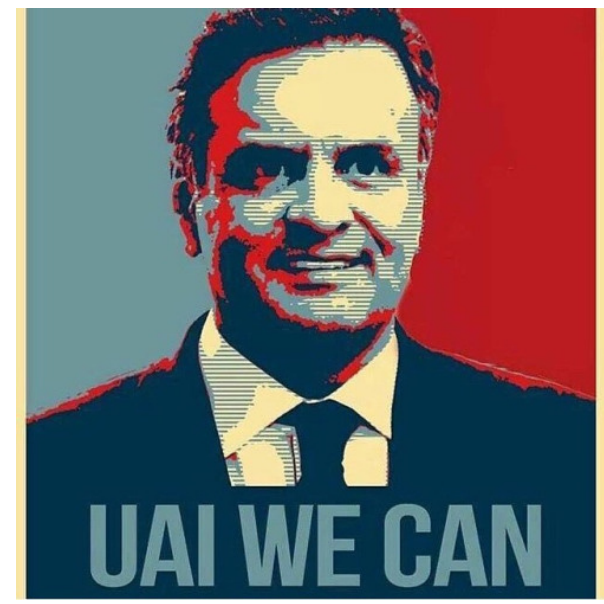

Figura 2

O ponto de vista incorporado pelo éthos conclamativo do hiperenunciador é o da crença na viabilidade da vitória eleitoral de Aécio. O uso da interjeição "uai" reforça a ligação do candidato com Minas Gerais, mas também propõe uma visada empática através do trocadilho irônico e popular. Os elementos gráficos do iconotexto recorrem ao tesauro de um eleitorado que sabe reconhecer a mensagem da bem-sucedida candidatura Obama, suscitando paralelos que vão da esperança no triunfo à própria personalidade política do pretendente tucano.

Passemos agora à aforização secundária, extraída de um texto, com o qual mantém fidelidade variável segundo a "força" do destacamento efetuado. As figuras 3 e 4 apresentam aforizações que podem ser consideradas frutos de destacamentos fortes, pois em diversos aspectos se dissociam dos respectivos textos fontes (MAINGUENEAU, 2012, p. 2). Mas essas dissociações possuem naturezas diversas.

"Bela, recatada e dólar" (figura 3) subverte de duas maneiras a manchete pretensamente elogiosa da revista Veja dedicada à primeira-dama Marcela Temer ("Bela, recatada e do lar", edição de 18 de abril de 2016): no âmbito iconográfico, transfere o referente do enunciado para o casal Eduardo Cunha e Cláudia Cruz, enquanto a sentença modifica o paratexto original a partir da assonância das suas 
últimas palavras ("do lar"), formando um substantivo derivado por aproximação fonética ("dólar"). O grupo nominal da pequena frase leva o leitor a buscar os sujeitos referenciados na fotografia, enquanto o próprio texto reitera a ancoragem do enunciado na memória de um já-dito com sentido antagônico. O efeito paródico do objeto resulta dessa dupla transgressão.

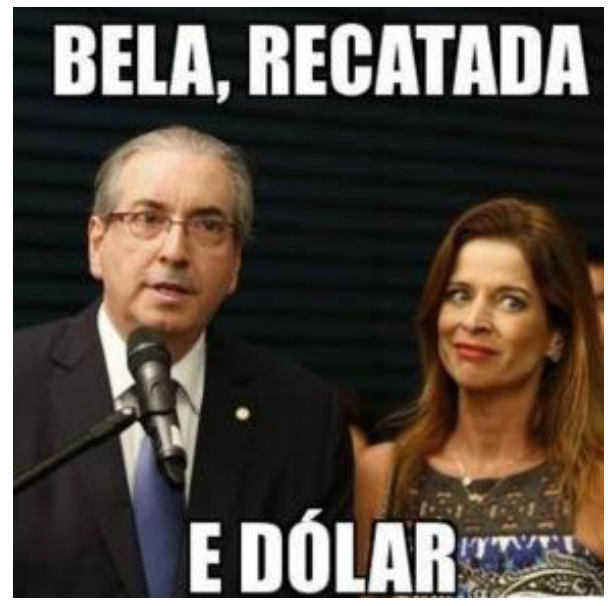

Figura 3

Já “Tchau, querida!" (figura 4) desloca o enunciado de seu contexto original, uma conversa telefônica entre o ex-presidente Luís Inácio Lula da Silva e a então presidente Dilma Rousseff. Além da subversão do gênero de discurso, o deslocamento denotativo se dá com a utilização de uma imagem colhida em outra circunstância, na qual Dilma aparece comovida. O sinal gráfico de exclamação (que confere ao texto um caráter imperativo) e a dramaticidade do flagrante fotográfico afluem para criar uma hiperenunciação autônoma, ligada a um posicionamento político oposto ao do autor e ao da interlocutora do enunciado fonte.

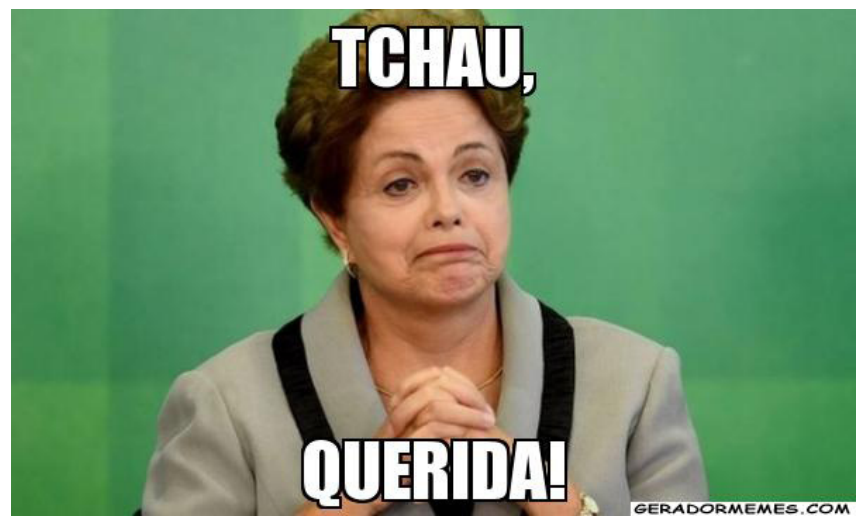

Figura 4 
Apesar de tantos desvios, as figuras 3 e 4 permanecem compreensíveis porque lidam com aforizações previamente estabilizadas no imaginário comum e pertencentes ao "regime de atualidade" que caracteriza o noticiário periódico (MAINGUENEAU, 2014, p. 123-124). É o enquadre informacional (idem, p. 119) do trecho da conversa telefônica divulgada por autoridades judiciais que permite a certa comunidade bem informada identificar a origem da despedida presente na figura 3. Da mesma forma, o enquadre testemunhal (ibidem, p. 121) que ligou a manchete da revista Veja à esposa de uma autoridade pública fornece os elementos necessários para o leitor compreender a ironia de sua transposição a outro casal famoso.

\section{PANAFORIZAÇÃO OU METAFORIZAÇÃO?}

Os meios digitais são pródigos em iconotextos que se apropriam dos mesmos destacamentos referidos acima, tanto os iconográficos quanto os textuais, com sentidos múltiplos e mesmo antagônicos. Isso demonstra o grau de disseminação que as aforizações originais tiveram na "pandemia" de intercâmbios midiáticos, configurando o fenômeno chamado por Maingueneau de panaforização,

(...) termo que combina o pan de "pandemia" e "aforização". A panaforização figura nas manchetes dos jornais, se infiltra nas conversações ordinárias, suscita debates de todas as espécies nas mídias: nos fóruns, talk-shows televisivos, no correio dos leitores etc., antes de desaparecer, substituída por outras (MAINGUENEAU, 2012, p. 4).

A autonomia que o uso descontextualizado confere à panaforização permite leituras ao mesmo tempo anafóricas (retrospectivas) e catafóricas (antecipativas), que atualizam memórias enciclopédicas em torno de já-ditos amplamente reconhecidos, para articular posicionamentos acerca de questões imediatas (idem, p. 12-13). O iconotexto da figura 3 faz da ancoragem situacional da panaforização primeira o mote de uma defesa do (então) futuro impeachment de Dilma Rousseff. A figura 4 retorna aos Temer para realçar paralelos possíveis com o ex-deputado e sua esposa (a diferença de idade dos cônjuges, por exemplo), enquanto a contração "dólar" insere o iconotexto no escândalo de corrupção que atingiu os retratados e levou à prisão de Eduardo Cunha.

Embora o conceito de panaforização tenha evidente relevância nos debates sobre os memes, não podemos adotar essa nomenclatura sem alguns cuidados prévios. Segundo o modelo proposto por Maingueneau, o destacamento panaforizador possui circulação efêmera nos suportes comunicativos, uma vigência limitada pelas dinâmicas novidadeiras do intercâmbio midiático. A distinção é importante, mas arriscada. Conforme apontei na problemática definição de "meme", não parece fácil estabelecer a fugacidade de uma mensagem qualquer em meio às intermitências e reconfigurações do universo digital. Além disso, as próprias redes interdiscursivas que envolvem os iconotextos analisados (e as panaforizações que os geraram) facilitam a perenização dos mesmos objetos, ou de outros com enunciados similares. 
Roberto Leiser Baronas (2013) detecta o impasse ao lidar com a pequena frase "A esperança venceu o medo". O autor sugere tomar esse tipo de fenômeno como metaforização:

Trata-se de uma pequena frase que assume o caráter de uma metáfora com intensa circulação, ou seja, uma frase que se presta por conta da sua constituição linguístico-discursiva (pregnância linguística e de sentidos) a estabelecer uma analogia de sentidos entre diferentes acontecimentos discursivos (BARONAS, 2013, p. 241-242).

Apesar da necessária ressalva no que tange à aforização proverbial ("Digame com quem andas que te direi quem és"), a adequação desse conceito aos demais enunciados ("Uai, we can", "Bela, recatada e dólar", "Tchau, querida!”) sugere tratar-se de um caminho profícuo para desenvolver o debate. Não apenas quanto a certa acepção vulgarizada de meme, mas também pelo que o prefixo "meta" aduz acerca das panaforizações geradas por outras panaforizações, com essa autoconsciência referencial tão característica dos iconotextos digitais.

\section{CONSIDERAÇÕES FINAIS}

As análises propostas visaram elucidar alguns processos de aforização no âmbito da iconotextualidade digital, numa dinâmica de complementaridade significativa entre a imagem e o enunciado que a acompanha. $\mathrm{O}$ objeto resultante agencia um duplo destacamento, simultaneamente iconográfico e textual, ambos responsáveis pelo efeito de aforização do conjunto. A dimensão linguística determina a natureza primária ou secundária das aforizações realizadas pelo iconotexto, enquanto a indexação denotativa da fotografia ajuda a contextualizar o enunciado, mobilizando uma série de conexões interdiscursivas que reforçam tomadas de posição acerca de temas contemporâneos.

Esse aspecto persuasivo possui claras afinidades com a aforização iconotextual hegemônica nos suportes impressos tradicionais, especialmente nos campos jornalístico e publicitário. Não por acaso, ambos são fontes privilegiadas do material apropriado na confecção dos memes: o destacamento prévio da esfera midiática estabiliza as imagens e os enunciados na memória discursiva da coletividade leitora, possibilitando seu reconhecimento posterior e, mais importante, a interpretação de suas reconfigurações. A própria disseminação do conteúdo audiovisual que circula na internet depende em larga medida da permanência de certos códigos de inteligibilidade herdados de suportes analógicos, nos quais o mecanismo de aforização desempenha papel relevante.

Os exemplos mencionados representam apenas microscopicamente o universo difuso e multifacetado da iconotextualidade digital, mas eles apontam para possíveis modelos referenciais de enunciação aforizante (provérbios, slogans, máximas, citações) que, com o necessário acréscimo das sobreasseverações, podem contribuir para o estudo dos impulsos peculiares de criação e compartilhamento desse tipo de objeto. Longe de esgotar as possibilidades analíticas do tema, especialmente no que tange à itinerância propiciada pelo hipertexto, a proposta 
visa contribuir para aliviar certa fragilidade conceitual que afeta o fenômeno vasto e difuso simplificado sob a alcunha de "meme" e que se origina, em parte, de uma tendência a supervalorizar o ineditismo revolucionário das comunicações via internet.

$\mathrm{O}$ esforço não está isento de riscos. Tanto o recorte iconotextual quanto o prisma discursivo suscitam comprometimentos com repertórios teóricos e metodológicos cuja adequação ao mundo digital ainda é tema de controvérsia. Mesmo o embasamento em Dominique Maingueneau para uma análise dos memes talvez merecesse ponderações acerca das mudanças que o autor vem apontando nos gêneros discursivos da internet, com resultados importantes para a cena englobante, a cena genérica e a cenografia dos enunciados (MAINGUENEAU, 2016). Mas os inegáveis aspectos inovadores da "textualidade navegante" não invalidam recortes analíticos nos quais esse aspecto seja secundário, inclusive sob um ponto de vista pragmático. Em outras palavras, trata-se de manter em perspectiva que a complexidade dos intercâmbios digitais abarca inclusive a reiteração ou a atualização de estratégias comunicativas estabelecidas muito antes da revolução tecnológica.

\section{REFERÊNCIAS}

BAKHTIN, Mikhail. Estética da criação verbal. 4 ed. São Paulo: Martins Fontes, 2003.

BARONAS, Roberto Leiser. Da panaforização à metaforização: o caso de uma pequena frase sem eira nem beira textual. Revista da ABRALIN, v.12, n.2, p. 219-248, jul./dez. 2013.

BARTHES, Roland. A retórica da imagem. In O óbvio e o obtuso: ensaios sobre fotografia, cinema, teatro e música. Rio de Janeiro: Nova Fronteira, 1999. p. 27-43.

BLACKMORE, Susan. The Meme Machine. Oxford: Oxford University Press, 1999.

DAWKINS, Richard. O gene egoísta. Belo Horizonte: Itatiaia; Editora da USP, 1979.

LUGRIN, Gilles. Généricité et intertextualité dans le discours publicitaire de presse écrite. Berna, Suíça, Éditions Peter Lang, 2006.

MAINGUENEAU, Dominique. A análise do discurso e suas fronteiras. Matraga, Rio de Janeiro, v.14, n.20, p.13-p.37, jan./jun. 2007.

MAIngueneAU, Dominique. Cenas da enunciação. Org: Sírio Possenti, Maria Cecília Pérez de Souza-e-Silva. São Paulo, Parábola Editorial: 2008.

MAINGUEnEAU, Dominique. Doze conceitos em análise do discurso. Org Sirio Possenti, Maria Cecília de Souza-e-Silva. São Paulo: Parábola Editorial, 2010.

MAINGUENEAU, Dominique. Aforização, enquadramento interpretativo e configuração humanista. In: MOMESSO, M. R. et al. (org.). Discurso e linguagens: objetos de análise e perspectivas teóricas. v.6, p. 15-35, 2011. Coleção Mestrado em Linguística. Disponível em publicacoes. 
unifran.br/index.php/colecaoMestradoEmLinguistica/article/view/542. Acesso em: 14 de setembro de 2017.

MAINGUENEAU, Dominique. Aforizações políticas, mídias e circulação de enunciados. Linguasagem, São Carlos, ed. 20, dez. 2012. Disponível em www.letras.ufscar.br/linguasagem/ edicao21\%. Acesso em 14 de setembro de 2017.

MAINGUENEAU, Dominique. Frases sem texto. São Paulo: Parábola Editorial, 2014

MAINGUENEAU, Dominique. Gêneros do Discurso e Web: existem os gêneros web? Revista da ABRALIN, v.15, n.3, p. 135-160, jul./dez. 2016. Disponível em revistas.ufpr.br/abralin/article/ view $/ 50230$. Acesso em 14 de setembro de 2017.

MANOVICH, Lev. The language of the new media. Cambridge: Massachusetts Institute of technology press, 2001. 